\title{
Personhood in a Communitarian Context
}

\author{
Barry Hallen
}

Morehouse College, U.S.A.

hallenbarry@gmail.com

DOI: http://dx.doi.org/10.4314/tp.v7i2.2

Thought and Practice: A Journal of the Philosophical Association of Kenya (PAK)

New Series, Vol.7 No.2, December 2015, pp.1-10

thoughtandpractice@gmail.com

http://ajol.info/index.php/tp

ISSN: 2076-7714 


\begin{abstract}
Theories regarding the nature and achievement of personhood in a communitarian context appear to differ in significant respects in the writings of several contemporary African philosophers. Ifeanyi Menkiti seems to regard ethnic differences as sufficient to warrant a national accommodation of multiculturalism with respect to moralities and attendant beliefs. Kwasi Wiredu argues that there is a substantive universal moral principle that undercuts such apparent and relatively superficial diversity. Communitarianism also seems to provide a better framework for explaining how a human being becomes a person than classical liberal theory as enunciated by someone like John Rawls.
\end{abstract}

\title{
Keywords
}

Communitarianism, liberalism, multiculturalism, personhood, Masolo, Menkiti, Rawls, Wiredu

\section{Introduction}

I want to focus on elements of communitarian theory in the writings of several contemporary African philosophers, and then explore areas where those elements may challenge one another as well as areas where they may overlap or supplement one another. The philosophers I am going to concentrate on are Ifeanyi Menkiti, Kwasi Wiredu and D.A. Masolo. I will also make brief reference to the work of John Rawls and liberal theory generally.

The elements I will focus on are as follows: the significance of personhood generally; Kwasi Wiredu's Principle of Sympathetic Impartiality; Ifeanyi Menkiti on problems of the African nation-state; pre-personhood in liberalism and communitarian theory; Menkiti on the transition to personhood. 


\section{Personhood}

The process a human being must go through in order to achieve personhood in a communitarian context is complex. That a human being will transition to personhood is certainly not a given - it is an achievement not only on the part of the individual, but also on the part of the community which labors, perfectly deliberately and responsibly, to transform human beings into "persons through acquiring and participating in the socially generated knowledge of norms and actions that we learn to live by in order to impose humaneness upon our humanness" (Masolo 2010, 155).

Western epistemology likes to point to the acquisition of language and the consequent enhanced ability to communicate as perhaps the most important dimension to social interaction. On a communitarian view linguistic ability is certainly not to be ignored (Menkiti 1984, 172; Masolo 2010, 142), but it is the moral transformation facilitated by those communicative skills that is more highly acclaimed. In the following mélange of passages about his native Akan culture, the Ghanaian philosopher Kwasi Wiredu puts it this way:

a human person is essentially the center of a thick set of concentric circles of obligations and responsibilities matched by rights and privileges (Wiredu 1992, 199).

... The theater of moral upbringing is the home, at parents' feet and within range of kinsmen's inputs. The mechanism is precept, example and correction. The temporal span of the process is lifelong (Wiredu 1992, 195).

.... The communalistic orientation of ... society ... means that an individual's image will depend rather crucially upon the extent to which his or her actions benefit others than himself [or herself], not, of course by accident or coincidence but by design. ... an individual who remained content with self-regarding successes [with self-interest] would be viewed as so circumscribed in outlook as not to merit the title of a real person (Wiredu 1992, 200).

There are those who defend this kind of social order for its humanitarian orientation that its enunciated, overriding concern is the welfare of all. They hold that being morally obligated to other persons and to the community generally in specific and 


\section{Barry Hallen}

meaningful ways makes for a social context in which the Other and the Self are equally and mutually prominent and dependent.

On the other hand, those of a so-called 'liberal'persuasion argue that given these ethical and moral priorities, a communitarian orientation subsumes the individual to the group in a manner that is (morally) repugnant. For them, the priority ought not to be to stipulate what rights the group has over the individual, but rather to stipulate what rights the individual has independently of the group, or as Masolo puts it, paraphrasing John Rawls, "the individual ... as the beneficiary of an equal right to the most extensive liberty that is compatible with a similar liberty for others" (Masolo 2010, 228).

Inevitably, it seems, in discussions of communitarian cultures, their value systems relating to personhood end up being presented as counterpoised to those said to be foundational to so-called liberal, democratic cultures and societies. In which case, 'traditional' Africa comes second once again, this time for not prioritizing individual rights and responsibilities, which becomes linked to any number of endemic social and political 'problems' ("tribalism", for example).

\section{Wiredu's Principle of Sympathetic Impartiality}

Kwasi Wiredu has sought to restructure this apparently irresolvable disagreement between communitarian theory and liberalism on the issue of individual rights by positing a universal moral principle that must, he says, "underlie any human society in order for it to qualify as a society," which he calls the Principle of Sympathetic Impartiality. For him, "What we need to do is to specify a principle of conduct such that without its recognition - which does not necessarily mean its invariable observance - the survival of [any] human society in a tolerable condition [his italics] would be inconceivable" (Wiredu 1996a, 29). He tells us that this Principle of Sympathetic Impartiality may be expressed by the imperative "Let your conduct at all times manifest a due concern for others" (Wiredu 1996a, 29). He acknowledges that the principle is reminiscent of the Golden Rule; but the reasoning he uses to justify its foundational status is as follows: "I suggest that it takes little imagination to foresee that life in any society in which everyone openly avowed the contrary of this principle 
and acted accordingly would inevitably be 'solitary, poor, nasty, brutish' [his italics], and probably short" (Wiredu 1996a, 29; my italics in part).

\section{Menkiti and the Nation-State}

The status of Wiredu's Principle of Sympathetic Impartiality as foundational would appear to become insignificant following the strategy advised by Ifeanyi Menkiti in his essay, "Philosophy and the State in Africa: Some Rawlsian Considerations". In many African nation-states today, Menkiti observes, there are multiple ethnic and linguistic communities whose cultural beliefs conflict and therefore have disparate interests that prove to be an obstacle to the emergence of a healthily unified body politic. For him, this is a situation in which "one holds out little hope for the possibility of coordinating the multiple intentions of a given citizen body through a unified moral or customary belief system" (Menkiti 2002, 37; my italics).

There are nation-states in Africa today that are the consequence of the arbitrary borders established during the period of European colonization. Their populations are composites of diverse ethnic groups that have little in common apart from a counterproductive ambition to gain control of the instruments of government and use them to advance their own community-specific interests. The provisional solution Menkiti proposes, derived from Rawls' strategy for risk aversion and the avoidance of destructive conflicts, is to have a 'bare bones' or 'thin' notion of national government:

let me simply note that if the African state succeeded in maintaining security, providing infrastructure, and facilitating trade, if it could understand itself as being an agent, in good faith, for these three things, then its functions would have been well served. ... The key insight in support of this position is an essentially Rawlsian one. The more individuals and communities are kept from forcing their comprehensive views on one another as a consequence of assigning some sort of moral majesty to the state and its organs, the better for the health of the body politic (Menkiti 2002, 38; my italics).

Of concern is that Wiredu's supposedly foundational Principle of Sympathetic Impartiality seems to pale into insignificance as a consequence of Menkiti's proposed scenario. Presumably Wiredu means for the principle also to be a substantive influence internal to the nation-state, on relations among people in multiple and 


\section{Barry Hallen}

disparate communities. If so, why can it not serve as the basis for some form of effective force and meaningful strategy that could override and temper conflicting communal interests in the African context? Wiredu also, of course, acknowledges the existence of differences between cultures and communities anywhere in the world. However, those differences, apparently, are not morally foundational and are therefore relegated by him to the status of supplementary categories of "customs" and "lifestyles". His point is that people who emphasize the relativity of moral values in different cultures are in fact themselves exaggerating the relatively contingent anomalies generated by differences in customs and lifestyles rather than foundational moral principles. He describes customs as "contingent norms of life, rather than forms of morality in the strict sense of this word" (Wiredu 1996a, 30), and argues that they could include "usages, traditions, manners, conventions, grammars, vocabularies, etiquette, fashions, aesthetic standards, observances, taboos, rituals, folkways, [and] mores" (Wiredu 1996a, 28; my italics).

With more specific respect to the interests of this essay, Wiredu argues that "The real difference between communalism and individualism has to do with custom and lifestyle rather than anything else. ... [because] both are, conceptually, of a kind and are distinct from morality in the strict sense" (Wiredu 1996b, 72; my italics). Apparently this model can also apply to different cultural manifestations of communalism within a single nation-state as well:

In this strict sense morality, from the standpoint of conduct, is the motivated pursuit of sympathetic impartiality. Such values as truthfulness, honesty, justice, chastity, etc. are simply aspects of sympathetic impartiality, and do not differentiate morality from culture to culture. At best, what the contingencies of culture may do is to introduce variations of detail in the definition of some of these values. Thus the concept of chastity in a polyandrous society will accommodate more diversified sexual contacts with men on the part of a woman than in a monogamous environment. These differing constraints on definition are, of course, constraints of custom, and do not flow from sympathetic impartiality by any stretch of logical implication. This is true of customs in general, and explains why, though morality, strictly so-called, does not and cannot differ from place to place, custom can and does. But since strict morality, at least as precept, is a social constraint, and any society will have one set of idiosyncrasies or another, what are often called alternative moralities will be found, on examination, to be composites of universal morality and contingent custom (Wiredu 1996a, 30). 
Thus, according to Wiredu, customs and lifestyles are primarily of instrumental and empirical value for highlighting the diversity of ways in which the universal moral principle is implemented in different cultures and communities. In which case there would seem to be good reason and certainly room for formulating national strategies that would target, invoke, and redirect or recast underlying currents of sympathetic impartiality as unifying, cross-communal motivations.

To conclude this point, is the Principle of Sympathetic Impartiality something that can be taken seriously in the African context as a reformative influence on motivation and behavior generally? Or is the Principle of Sympathetic Impartiality better appreciated as something that effectively applies only internally to members of a specific cultural community? Or, again, is the Principle of Sympathetic Impartiality one of those hypothetical ideas that philosophers are said to be prone to invent, but when it comes to the real world, are sometimes difficult to substantiate?

\section{Pre-Personhood in Liberalism and Communitarian Theory}

When reviewing the narratives relating to social contract theory, or to Rawls' "original position", what I find relevant to the interests of this essay is the silence of liberal theory when it comes to accounting for the origin of the rational, mature human beings who are a party, in fact essential, to the social contract. Liberal theory may have much of interest and value to say about contracting individuals and their rights and freedoms; but what about the social context that produced those individuals when they were in the pre-personhood stage? Does not liberal theory have to presuppose or presume some form of social context that produces the rational, mature individuals who enter into the social contract or who become engaged in the exercise consequent to what rawls refers to as "the veil of ignorance"?

I do not want to misspeak on this issue. I know there is nothing original about my raising this point. I do appreciate the justificatory nature of discussions relating to the contract with respect to its presuppositions. Still, on historical, anthropological, simply empirical grounds, the contracting individuals are not autochthonous and, as Annette Baier $(1988$; 1994) among others has suggested, must be the products of 


\section{Barry Hallen}

some forms of affective as well as reasoned human relationships in order to be capable of contracting.

\section{Menkiti on the Transition to Personhood}

Another of Ifeanyi Menkiti's insightful comparisons between Rawls' liberalism (Rawls 1999; 2001) and African communitarianism concerns this pre-personhood period in a human being's lifetime. However, I wonder whether on this occasion Menkiti perhaps understates the strengths of his own communal orientation and therefore is a bit too generous to his old mentor, Professor Rawls. This relates to the transition from what I am calling pre-personhood to full-blown personhood. Menkiti suggests that Rawls and communitarian theory share something in common with respect to recognizing the essential and important change that takes place when an individual transitions from childhood and youth to being a mature, rational, responsible person in the full sense of the term.

Speaking on behalf of Rawls, Menkiti puts it this way with respect to liberalism's view of the necessary condition that promotes the transition from pre-personhood to personhood:

Rawls makes explicit part of what is meant by the general ethical requirement of respect for persons, noting that those who are capable of a sense of justice are owed the duties of justice, with this capability construed in its sense of a potentiality which may or may not have been realized (Menkiti 2004, 330; my italics).

Menkiti addresses the same issue with respect to a communitarian context, stating that such a society tends:

to be guarded in its attitude toward the young, though still continuing to be open-minded until they, the young, show themselves capable of becoming full participants in communal life, through the discharge of the various obligations defined by their stations. For it is the carrying out of these obligations that transforms them from the it-status of early childhood, marked by an absence of moral function, into the personstatus of later years, marked by a widened maturity of ethical sense (Menkiti 2004, 330).

The point being that communitarian theory, once again, does a better job of speaking to this transitional period than liberalism. Communitarian theory has no reservations about prescribing in reasonably glowing terms the process of education the 
child/youth undergoes while clasped in the not always tender embrace of the extended family. On the other hand, liberal theory, again, can only posit, only rather vaguely presuppose, what the origins of the full-blown individual might involve without explaining how that person comes to be. Menkiti does not enthusiastically score one for communitarianism on this point, but it seems to me that he certainly could.

\section{Conclusion}

One noteworthy development in many contemporary accounts of the communitarian character of African cultures and societies is that they no longer are introduced with apologetic rhetoric for not meeting the 'standards' set by liberalism for individual liberties. Nor are they essentially justified by some sort of muted appeal to 'tradition'. Today African philosophers are reevaluating the communitarian pasts and presents of their cultures as a heritage that has genuinely positive attributes, though that heritage will need to be refined if it is to carry over into the present day. Communalism therefore deserves to be considered as a worthy alternative to the individualism that continues to be touted by liberal theory as deserving of unquestioned universal acclaim. 


\section{References}

Baier, Annette. 1988. "Pilgrim's Progress: Review of David Gauthier, Morals by Agreement". Canadian Journal of Philosophy, Vol.18 No.2, pp.315-330.

--. 1994. Moral Prejudices: Essays on Ethics. Cambridge: Harvard University Press.

Masolo, D.A. 2010. Self and Community in a Changing World. Bloomington: Indiana University Press.

Menkiti, Ifeanyi. 1984. "Person and Community in African Traditional Thought". Wright, Richard ed. African Philosophy: An Introduction. Washington, D.C.: University Press of America.

--. 2002. "Philosophy and the State in Africa: Some Rawlsian Considerations". Philosophia Africana, Vol.5 No.2, pp.35-51.

--. 2004. "On the Normative Conception of a Person". Wiredu, Kwasi ed. A Companion to African Philosophy. Oxford: Blackwell, pp.324-331.

Rawls, John. 1999. A Theory of Justice, Revized Edition. Cambridge: Belknap Press. --. 2001. The Law of Peoples. Cambridge: Harvard University Press.

Wiredu, Kwasi. 1992. "Moral Foundations of an African Culture". Chapter 9 in Person and Community: Ghanaian Philosophical Studies, I. Washington, D.C.: The Council for Research in Values and Philosophy, pp.193-206.

--. 1996a. "Are There Cultural Universals?" Chapter 3 in Cultural Universals and Particulars: An African Perspective. Bloomington: Indiana University Press, pp.21-33.

--. 1996b. "Custom and Morality: A Comparative Analysis of Some African and Western Conceptions of Morals". Chapter 6 in Cultural Universals and Particulars: An African Perspective. Bloomington: Indiana University Press, pp.61-78. 